\title{
Intrathyroidal Lymphoepithelial (Branchial) Cyst: Diagnostic and Management Challenge of a Rare Entity
}

\author{
${ }^{1}$ Christos S Christoforides, ${ }^{2}$ loannis Papandrikos, ${ }^{3}$ Ilias Zorbas, ${ }^{4}$ Gerasimos Kritikos, ${ }^{5}$ Ioannis Pateras, ${ }^{6}$ Dimitrios
} Vlachodimitropoulos, ${ }^{7}$ Angelos Kalovidouris, ${ }^{8}$ Kyriakos Vamvakidis

\begin{abstract}
Intrathyroidal lymphoepithelial (branchial) cysts are very rare, and only few cases have been previously reported worldwide. Here, we report on a case of a male patient with such a rare histological finding after a routine left hemithyroidectomy performed for a nearly $4 \mathrm{~cm}$ cystic left thyroid lobe lesion. The patient was an 80-year-old man, fact that makes, to our knowledge, our patient the oldest in the current literature. Through a review of the existing literature, we concluded that although some entities are extremely rare, they should also be taken under consideration in everyday clinical differential diagnosis of otherwise common medical cases, such as our presented case. Such cases pose a differential dilemma for the clinical doctor in order to make a correct diagnosis, if that is possible, and then proceed with the efficient treatment.
\end{abstract}

Keywords: Branchial cyst, Case report, Intrathyroidal, Lymphoepithelial cyst, Rare, Thyroid cyst.

How to cite this article: Christoforides CS, Papandrikos I, Zorbas I, Kritikos G, Pateras I, Vlachodimitropoulos D, Kalovidouris A, Vamvakidis K. Intrathyroidal Lymphoepithelial (Branchial) Cyst: Diagnostic and Management Challenge of a Rare Entity. World J Endoc Surg 2018;10(2):137-141.

Source of support: Nil

Conflict of interest: None

\section{INTRODUCTION}

Lymphoepithelial (branchial) cysts are common in the lateral neck, but there are also rare reports of these lesions in unusual locations, such as the oral cavity, ${ }^{1}$ thymus, parotid gland, ${ }^{2}$ pancreas, ${ }^{3}$ and thyroid..$^{5-8}$ First reported

\footnotetext{
${ }^{1}$ Deputy Director, ${ }^{2-5}$ Consultant Surgeon, ${ }^{6,7}$ Associate Professor ${ }^{8}$ Director

1-4,8Department of Endocrine Surgery, Henry Dunant Hospital Center, Athens, Greece

5Department of General Surgery, "Mamatsio" General Hospital of Kozani, Kozani, Greece

${ }^{6}$ Department of Public Health, National and Kapodistrian University of Athens, Medical School, Athens, Greece

${ }^{7}$ Department of Radiology, National and Kapodistrian University of Athens, Medical School, Athens, Greece

Corresponding Author: Christos S Christoforides, Deputy Director, Department of Endocrine Surgery, Henry Dunant Hospital Center, Athens, Greece, e-mail: christofchris@gmail. com
}

by Louis et al, ${ }^{9}$ intrathyroidal lymphoepithelial cysts are extremely rare lesions with, to our knowledge, less than 30 cases described in the English medical literature.-15 Our case represents the oldest-80 years old-patient described in the literature with such an uncommon lesion. The preoperative diagnosis is very difficult and in the majority of the cases, it is made after the histological features are revealed. Through this case presentation and review of the current English literature, we are focusing on the characteristics, the diagnostic dilemmas, and the management of this uncommon entity.

\section{CASE REPORT}

An 80-year-old male patient was referred to us from his endocrinologist with a gradually growing thyroid lesion. There was no associated pain, hoarseness of voice, or obstructive symptoms, and the results of his thyroid function were normal.

A power Doppler sonogram and a computed tomography of his neck revealed diffuse heterogeneity of the thyroid gland with a large $(3.8 \mathrm{~cm})$ cystic nodule at the left margin of the isthmus (Fig. 1), and two other smaller lesions up to $1.1 \mathrm{~cm}$ on the left lobe and $2.8 \mathrm{~cm}$ on the right lobe of the gland without suspicious characteristics. There were no pathologically enlarged or in other way suspicious cervical lymph nodes. A sonographically guided fine-needle aspiration of the cystic $3.8 \mathrm{~cm}$ left lobe

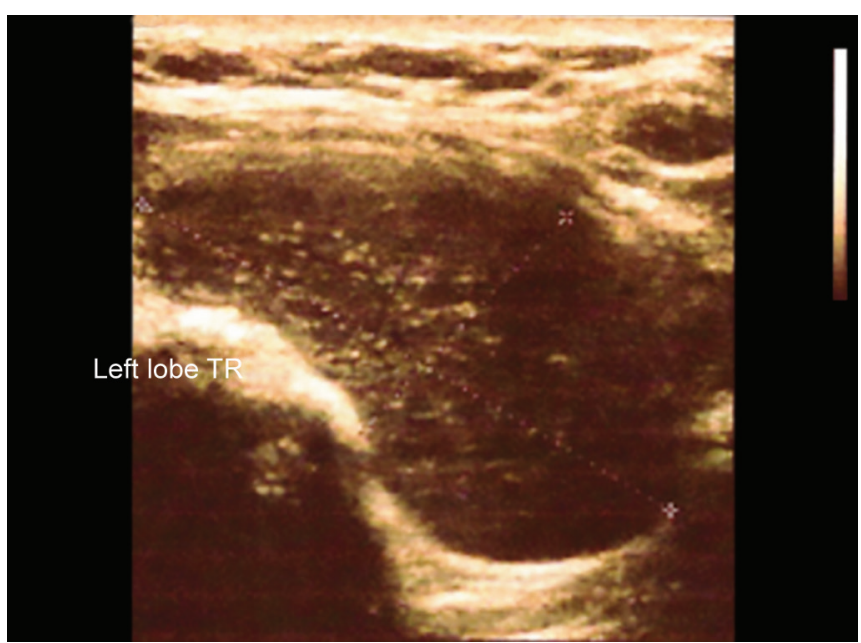

Fig. 1: Sonographic image of the left lobe $3.8 \mathrm{~cm}$ cystic lesion 


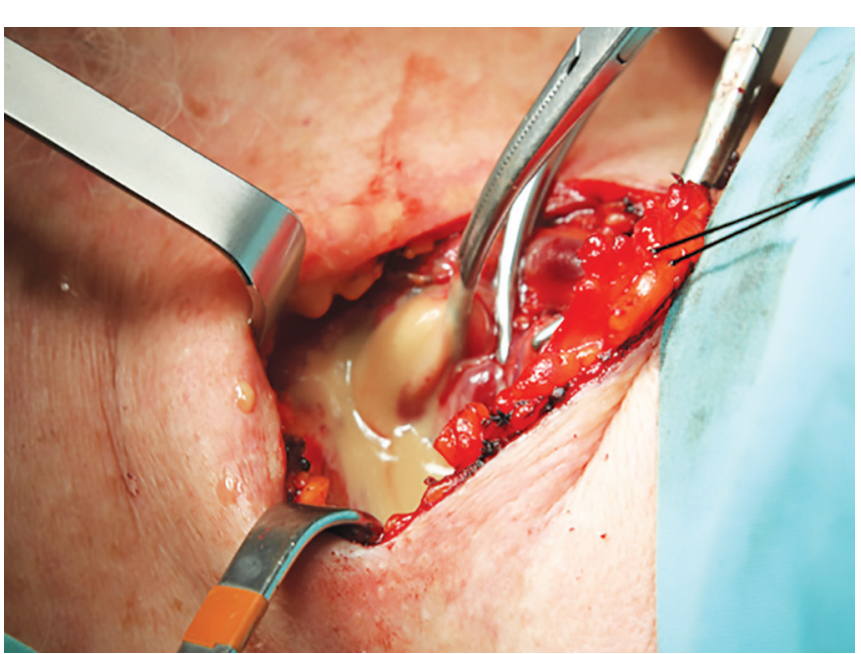

Fig. 2: Intraoperative image of the ruptured cystic lesion and its yellowish, pus-like content

lesion showed no signs of malignancy and on cytologic smears, there were some isolated follicular cells, many lymphocytes, and some colloid depositions. Repeated fine-needle aspirations from the right lobe lesion revealed a solid pure colloid thyroid nodule. The right lobe nodule was in an annual sonographical monitoring without significant changes for the last 4 years. The fact that the dominant left lobe-isthmus nodule-doubled its size from previous (18 months before) examination led us to the decision to perform a thyroidectomy.

During the operation, there was a rupture of the cystic lesion and the surgical field was covered by its content, a yellowish, pus-like thick fluid (Fig. 2). This unexpected finding and the fact that there were no other palpable or macroscopically seen suspicious lesions on the right lobe led us to perform a left hemithyroidectomy and isthmectomy. Aspiration from the cyst's content was sent for a cytology and microbiology examination and the surgical specimen was sent to histopathologists. The postoperative period was uneventful and the patient was discharged on the second postoperative day, after a thorough explanation of the surgical findings and the operation performed.

The results from the cytology showed many mature squamous cells, some neutrophils, plenty of cholesterol crystals, and some red blood cells, but no sign of malignancy. The microbiology examination did not reveal any pathogens. What was not expected was the result of the histopathology that showed a $3.5 \mathrm{~cm}$ cystic lesion of the left lobe with coexistence of diffuse lymphocytic infiltration with lymphoid follicle formation, all of them characteristic features of Hashimoto's thyroiditis. The cystic lesion had a thin fibrous wall that was lined with flattened squamous cell epithelium with typical characteristics (Fig. 3). Surrounding the epithelial lining were lymphoid follicles (Fig. 4). The histological findings are those of an intrathyroidal branchial cyst with chronic lymphocytic

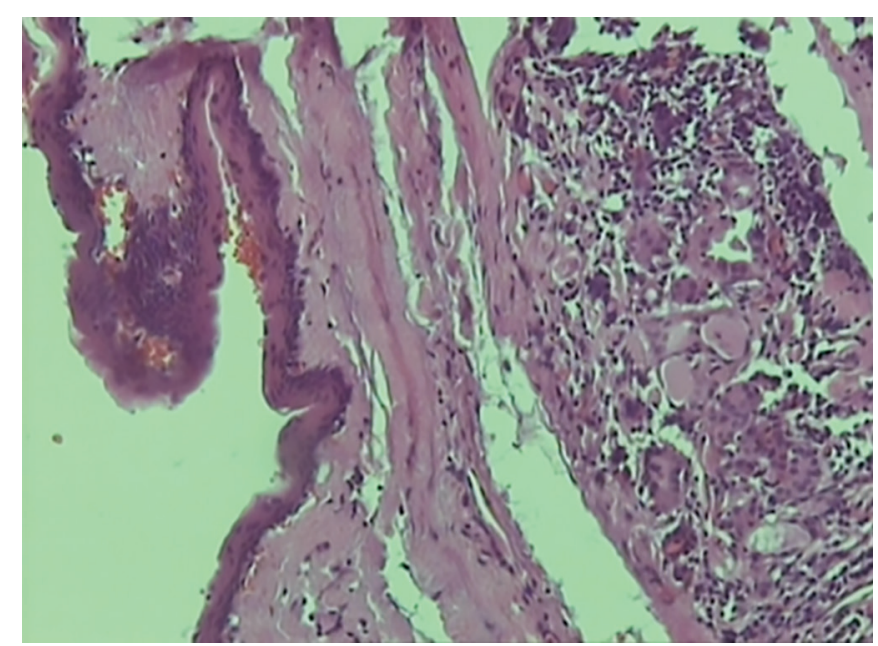

Fig. 3: The squamous epithelial cells of the cyst

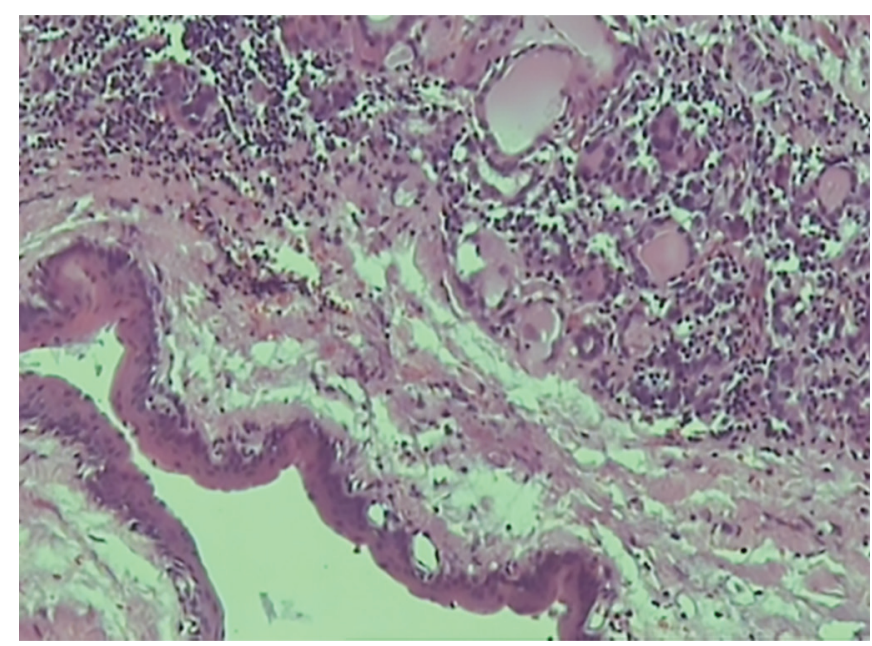

Fig. 4: Outside the cyst, normal thyroid tissue and lymphocytic aggregates are observed

thyroiditis (Hashimoto). Immunohistochemically, the epithelial lining was reactive for keratin, but not reactive for thyroglobulin or carcinoembryonic antigen. Adjacent to the cystic lesion position, a $0.3 \mathrm{~cm}$ papillary microcarcinoma with nonaggressive characteristics, limited within the thyroid parenchyma, was identified.

Those characteristics of the malignancy along with the patient's advanced age and intraoperative dangers of a completion thyroidectomy led his endocrinologist and us to prefer close monitoring instead of reoperation. Patient did not need any supplementary therapy for his thyroid function.

\section{DISCUSSION}

Branchial anomalies may result from the abnormal persistence of branchial apparatus remnants, which are usually present around each of the developed branchial derivatives. They are classified as cysts, sinuses, or fistulas. According to a recent publication, lesions from 
ultimobranchial body can be classified as solid cell nests, solid cell nests with focal cystic change, cystic solid cell nests, branchial cleft-like cyst and Warthin tumor-like lesions. ${ }^{15}$ A branchial cyst is an epitheliallined structure without an external opening that is mostly located in the lateral areas of the head and neck. Most of thyroid cystic lesions are the result of degeneration on the ground of nodular goiter or neoplasm. ${ }^{16}$ In literature, there are rare descriptions of cystic lesions with epithelial lining and morphology compatible with those of branchial cysts. ${ }^{17}$

Commonly, lymphoepithelial branchial cysts are located in the lateral neck. There is a theory supporting that the intrathyroidal appearance of branchial cysts is probably due to branchial remnants. This is supported by occasional intrathyroidal presence of other branchiaederived structures, such as thymic and parathyroid tissue. Some of the previously reported cases agree and reinforce this theory. 1,12

Moreover, the presence of squamous epithelium (as seen within the walls of these cysts) is not common within the thyroid gland. Therefore, considering the source of squamous cells within the thyroid might give us a lead as far as the origin of intrathyroidal branchial cysts is concerned. ${ }^{11}$ Squamous epithelium in the thyroid may be derived from thymic remnants, thyroglossal duct remnants, metaplastic follicular cells, ultimobranchial remnants, and tumors containing squamous cells. ${ }^{16}$

Thymic remnants have been found in the lateral parts of the thyroid gland, in one of the previously reported cases. They are likely to be present because the thymus has a close relationship with thyroid gland embryologically. This was not identified in our case. On the contrary, thyroglossal remnants can also be the source of squamous cells, but in this case, they are located centrally than in the lateral lobes. ${ }^{17}$

In thyroid glands affected by inflammation, squamous cells can also be found and probably originate from remnants of the ultimobranchial body, also known as solid cell nests. Also, tumors containing squamous epithelium have a range of cyst like lesions, and in these neoplasms, squamous metaplasia that has undergone malignant degeneration is most likely to have taken place. $^{18-21}$

Interestingly, some of the previously reported cases have occurred in thyroid glands containing a separate papillary carcinoma or even in some cases, a thyroid carcinoma located in the cyst. This could suggest a causal relationship between the two entities, but it seems more likely that these were coincidental findings. ${ }^{4,22-25}$ Coincidental or not, in our reported case, a $0.3 \mathrm{~cm}$ area of papillary microcarcinoma was also found.
The fact that the number of reported cases is very small and so do the experience and knowledge in this rare pathological finding the controversy remain over the origin of the intrathyroidal branchial cysts. Through the review of the limited literature, it is most likely, from the majority of authors, that they are remnants of the ultimobranchial body (solid cell nests). They develop from the fourth and fifth branchial pouch complex along with the thymus and parathyroid tissue, later incorporated within the lateral lobes of the thyroid as small cystic and solid cell nests. ${ }^{18,22}$

Another question is raised as far as their relation and strong association with Hashimoto's thyroiditis. It is not an absolute prerequisite, but the presence of lymphocytic infiltration adjacent to the cyst is a consistent finding. This can lead us to the assumption that intrathyroidal branchial cysts can arise whenever inflammation of any type is present. Some speculate that thyroiditis may induce enlargement of a previously existing intrathyroidal branchial cyst. The overwhelming majority of the previously reported cases are associated with thyroiditis. ${ }^{8}$

In view of the rarity of this lesion, it is unlikely to have a preoperative diagnosis. There are no specific radiological findings that can lead us to diagnosis and only a suspicion can be raised when the aspiration of a cystic lesion gives us yellowish, pus-like, thick fluid. ${ }^{13}$ The diagnosis, as in all previously reported cases, can only be suggested by histopathological confirmation. Therefore, we generally suggest when thyroid cysts are detected by ultrasound examination to determine through aspiration its content and whether it is a colloid or a true epithelial thyroid cyst. A definite diagnosis will be made postoperatively, but depending on the findings, intrathyroidal branchial cysts should be considered in the differential diagnosis.

The review of the 29, in English literature to our knowledge, previously reported cases reveals that 20 cases occurred in women and 8 in men, while in one case, the gender is not reported. The mean patient age at the time of diagnosis was 44.3 years (7-77 years), while our patient seems to be the oldest reported until today. The distribution of these cystic lesions in the thyroid gland is difficult to establish since total thyroidectomy occurred in only 13 of the reported cases, while the rest consisted of lobectomies alone. Of those with total thyroidectomy, seven showed bilateral and the remaining six unilateral involvement only. Papillary carcinoma was found in only five of the previously reported cases, as well as in our case. Lymphoid tissue associated with the cysts was present in all reported cases and was located in the wall of the cyst, just beneath the epithelium. Lymphoid infiltration in the background thyroid parenchyma and changes of 
Hashimoto's thyroiditis were seen in 13 of the previously reported cases, as well as in our case, and in 10 of the rest, a diagnosis of chronic lymphocytic thyroiditis had been rendered. The remaining six cases showed different degrees of chronic inflammation. ${ }^{4-10,12-16,22-31}$

\section{CONCLUSION}

We report on a case of an 80-year-old patient with a unilateral intrathyroidal branchial (lymphoepithelial) cyst and a coexistent papillary carcinoma. Branchial cysts of the thyroid are relatively rare lesions that seem to arise from intrathyroidal solid cell nest remnants of branchial derivatives, such as the ultimobranchial bodies. These cysts may become noticeable as solitary or multiple, unilateral or bilateral thyroid masses that can simulate neoplasms. They are usually present in thyroid glands affected by chronic inflammatory processes, but there are also reports of them in otherwise histologically unremarkable thyroid glands. They are reported in both sexes and the age of diagnosis varies from early 30 s to early 80 s (as seen in our reported case). Some of the cases occurred in thyroid glands containing papillary neoplasms without a definitive association between the two entities being established.

Intrathyroidal branchial cysts are relatively newly described entities with only few cases reported worldwide. Thus, any data from future cases will improve our understanding of the pathogenesis, possible preoperative diagnosis and proper management.

\section{REFERENCES}

1. Giunta J, Cataldo E. Lymphoepithelial cysts of the oral mucosa. Oral Surg 1973 Jan;35(1):77-84.

2. Weidner N, Geisinger KR, Sterling RT, Miller TR, Yen TS. Benign lymphoepithelial cysts of the parotid gland: a histologic, cytologic, and ultrastructural study. Am J Clin Pathol 1986 Apr;85(4):395-401.

3. Truong LD, Rangdaeng S, Jordan PH Jr. Lymphoepithelial cyst of the pancreas. Am J Surg Pathol 1987 Nov;11(11):899-903.

4. Apel RL, Asa SL, Chalvardjian A, LiVolsi VA. Intrathyroidal lymphoepithelial cysts of probable branchial origin. Hum Pathol 1994 Nov;25(11):1238-1242.

5. Delabie J, De Wolf-Peeters C, Cappelle L, Van Damme B, Desmet V. Branchial cleft like cysts of the thyroid. Am J Surg Pathol 1990;14:1165-1171.

6. Haba R, Miki H, Kobayashi S, Kushida Y, Saoo K, Hirakawa E, Ohmori M. Intrathyroidal branchial cleft-like cyst in chronic thyroiditis. Pathol Int 2000 Nov;50(11):897-900.

7. Lim-Tio SW, Judson R, Busmanis I, Zajac JD. An intrathyroidal branchial cyst: a case report. Aust N Z J Surg 1992 Oct;62(10):826-828.

8. Ryska A, Vokurka J, Michal M, Ludvikova M. Intrathyroidal epithelial cyst: a report of two cases not associated with Hashimoto's thyroiditis. Pathol Res Pract 1997 Dec;193(11-12): 777-781.
9. Louis DN, Vickery AL Jr, Rosai J, Wang CA. Multiple branchial cleft-like cysts in Hashimoto's thyroiditis. Am J Surg Pathol 1989 Jan;13(1):45-49.

10. Carter E, Ulusarac O. Lymphoepithelial cysts of the thyroid gland: a case report and review of the literature. Arch Pathol Lab Med 2003 Apr;127(4):e205-e208.

11. Ahuja AT, Chang AR, To E, Pang P, Ching AS, King AD, Metreweli C. Intrathyroidal lymphoepithelial (Branchial) cyst: sonographic features of a rare lesion. AJNR Am J Neuroradiol 2000 Aug;21(7):1340-1343.

12. Kondi-Pafiti A, Kontogianni KI, Smyrniotis V, Voros D. Intrathyroid lymphoepithelial (branchial) cyst. A report of two cases and review of the literature. Hellenic Arch Pathol 2002;16(1):31-35.

13. Nakazawa T, Kondo T, Oishi N, Tahara I, Kasai K, Inoue T, Mochizuki K, Katoh R. Branchial cleft-like cysts involving 3 different organs: thyroid gland, thymus, and parotid gland. Medicine (Baltimore) 2015 Oct;94(42):e1758.

14. Miyazaki M, Kiuchi S, Fujioka Y. Branchial cleft-like cysts in Hashimoto's thyroiditis: a case report and literature review. Pathol Int 2016 May;66(5):297-301.

15. Srbecka K, Michalova K, Curcikova R, Michal MJr, Dubova M, Svajdler M, Michal M, Daum O. Spectrum of lesions derived from branchial arches occurring in the thyroid: from solid cell nests to tumors. Virchows Arch 2017 Sep;471(3): 393-400.

16. Lee HJ, Kim EK, Hong S. Sonographic detection of intrathyroidal branchial cleft cyst: a case report. Korean J Radiol 2006 Apr-Jun;7(2):149-151.

17. LiVolsi VA, Merino MJ. Squamous cells in the human thyroid gland. Am J Surg Pathol 1978 Jun;2(2):133-140.

18. Williams ED, Toyn CE, Harach HR. The ultimobranchial gland and congenital thyroid abnormalities in man. J Pathol 1989 Oct;159(2):135-141.

19. Harach HR. Solid cell nests of the thyroid. J Pathol 1988 Jul;155(3):191-200.

20. Beckner ME, Shultz JJ, Richardson T. Solid and cystic ultimobranchial body remnants in the thyroid. Arch Pathol Lab Med 1990 Oct;114(10):1049-1052.

21. Yamaoka Y. Solid cell nest (SCN) of the human thyroid gland. Acta Pathol Jpn 1973 Aug;23(3):493-506.

22. Wtanabe I, Kobayashi K, Yamaguchi M, Kasai M. Multilocular lymphoepithelial cyst in the thyroid accompanied with a minute thyroid carcinoma. Pathol Int 1995 Dec;45(12): 965-970.

23. Cho JS, Shin SH, Kim HK, Lee JS, Park MH, Yoon JH, Jegal YJ. Primary papillary carcinoma originated from a branchial cleft cyst. J Korean Surg Soc 2011 Dec;81(Suppl 1): S12-S16.

24. Ruhl DS, Sheridan MF, Sniezek JC. Papillary thyroid carcinoma in a branchial cleft cyst without a thyroid primary: navigating a diagnostic dilemma. Case Rep Otolaryngol 2013 Jul;2013:405342.

25. Gollahalli PK, Chikkannaiah P, Annam V. Primary papillary carcinoma of the thyroid arising in a branchial cyst: case report and review of the literature. Ear Nose Throat J 2013 Feb;92(2):E3-E5.

26. Carney JA. Thyroid cysts. Am J Surg Pathol 1989 Dec; 13(12):1072-1074.

27. Radhi JM, Clive PJ. Intrathyroidal branchial cleft cyst in Hashimoto's thyroiditis. AJR Am J Roentgenol 1994 Jul;163(1):229. 
28. Asanuma K, Nishio A, Itoh N, Kasuga Y, Amano J. Multiple branchial cleft-like cysts in a female patient with Hashimoto's thyroiditis. Endocr J 2000 Jun;47(3):303-307.

29. Cassarino DS, Milas M, Folpe AL. Bilateral intrathyroidal lymphoepithelial cysts. Arch Pathol Lab Med 2003 Feb;127(2):251-252.
30. Park JY, Kim GY, Suh YL. Intrathyroidal branchial cleft-like cyst with heterotopic salivary gland-type tissue. Pediatr Dev Pathol 2004 May-Jun;7(3):262-267.

31. Michal M, Mukensnabl P, Kazakov DV. Branchial-like cysts of the thyroid associated with solid cell nests. Pathol Int 2006 Mar;56(3):150-153 